\title{
Effect of the dietary polyphenolic fraction of chicory root, peel, seed and leaf extracts on caecal fermentation and blood parameters in rats fed diets containing prebiotic fructans
}

\author{
Jerzy Juśkiewicz $^{1 *}$, Zenon Zduńczyk ${ }^{1}$, Ewa Żary-Sikorska ${ }^{2}$, Bogusław Król ${ }^{3}$, Joanna Milala ${ }^{3}$ and \\ Adam Jurgoński ${ }^{1}$ \\ ${ }^{1}$ Institute of Animal Reproduction and Food Research of the Polish Academy of Sciences, 10 Tuwima Street, 10-747 Olsztyn, \\ Poland \\ ${ }^{2}$ Department of Food Technology, Faculty of Agriculture and Biotechnology, University of Technology and Life Sciences, \\ 20 Kordeckiego Street, 85-225 Bydgoszcz, Poland \\ ${ }^{3}$ Institute of Chemical Technology, Technical University of Eódż, 4/10 Stefanowskiego Street, 90-924 Eódż, Poland \\ (Received 25 May 2010 - Revised 22 September 2010 - Accepted 24 September 2010 - First published online 7 December 2010)
}

\begin{abstract}
The aim of this $28 \mathrm{~d}$ experiment was to examine the physiological response of growing rats to a dietary combination of prebiotic chicory fructans, with polyphenols originating from different parts of the chicory plant, i.e. roots, root peels, seeds and leaves. A total of forty rats were assigned to groups fed the following diets characterised by a similar content of oligofructose and inulin: control, with $10 \%$ of a root extract (a low level of dietary polyphenols, $0.05 \%$ ), with $6.5 \%$ of a root peel extract (a medium level of dietary polyphenols, $0 \cdot 107 \%$ ), with a combination of $8 \%$ of a peel extract and $0.8 \%$ of a seed extract (a high level of dietary polyphenols, $0.208 \%$ ) and with $2 \cdot 5 \%$ of a leaf extract (a medium level of dietary polyphenols, $0 \cdot 106 \%$, with chicoric acid constituting half of them). Chicory seeds are the richest source of polyphenols, especially abundant in dicaffeoylquinic acids. When applied as a dietary supplement, the mixture of monocaffeoylquinic and dicaffeoylquinic acids, from the extracts made of roots, root peels and seeds, elicited more favourable changes in parameters of the antioxidative status of the body and in the activity of bacterial $\beta$-glucuronidase in the faeces and caecal digesta. In turn, the extract from chicory leaves, containing considerable quantities of chicoric acid and polyphenolic glycosides, apart from chlorogenic acids, also triggered desirable changes in the lipid profile of the blood serum. The high concentration of polyphenols in the extracts examined enables their application as dietary supplements to be administered in low doses.
\end{abstract}

Key words: Chicory: Polyphenols: Fructans: Caecum: Rats

In the last two decades, an increasing interest has been observed in the health-promoting properties of particular food constituents, including dietary fibre-polyphenolic complexes. Chicory belongs to plants of the Compositae family, accumulating energy in the form of the fructan inulin, the physiological (i.e. prebiotic) properties of which have been described in numerous studies. The available literature lacks comprehensive reports on the contents of individual active substances in the leaves and roots of chicory, particularly polyphenolic compounds. In the case of artichoke (Cynara scolymus L.), the leaves of which contain a similar array of biologically active substances as in chicory, the data are more compendious and more easily available ${ }^{(1)}$. The main components of chicory roots and leaves belonging to a group of phenolic compounds include monocaffeoylquinic acids (MCQA, e.g. chlorogenic acid being an ester of quinic and caffeic acids), dicaffeoylquinic acids (DCQA, e.g. cynarine, i.e. 1,5-DCQA) and chicoric acid. It has been reported that a high percentage of dietary chlorogenic and caffeic acids is not absorbed from the gastrointestinal tract of humans and may exhibit a variety of intestinal effects ${ }^{(2)}$. In vitro investigations have demonstrated that chlorogenic acid inhibits the process of DNA damage and the synthesis of mutagenic and carcinogenic $N$-nitroso compounds ${ }^{(3)}$. In turn, caffeic acid and its derivatives have been shown to

\footnotetext{
Abbreviations: ACL, antioxidant capacity of lipid-soluble substances; ACW, antioxidant capacity of water-soluble substances; C group, control group; CQA, caffeoylquinic acids; DCQA, dicaffeoylquinic acids; MCQA, monocaffeoylquinic acids; PH, diet supplemented with $8 \%$ of peel extract and $0 \cdot 8 \%$ of seed extract; PL, diet supplemented with $10 \%$ of root extract; PM, diet supplemented with $6.5 \%$ of peel extract; PMc, diet supplemented with $2.5 \%$ of leaf extract with $0 \cdot 106 \%$ of total phenolics; TBARS, thiobarbituric acid-reactive substances.
}

*Corresponding author: J. Juśkiewicz, fax +48 8952401 24, email j.juskiewicz@pan.olsztyn.pl 
display antiproliferative activity in vitro against neoplastic cells $^{(4)}$. Both dietary chlorogenic and caffeic acids may mitigate the risk of CVD through diminished oxidation of both the LDL-cholesterol fraction and total cholesterol ${ }^{(5)}$. Also, in other studies, chlorogenic acid was found to decrease the levels of total cholesterol and TAG in the blood serum of obese, hyperlipidaemic and insulin-resistant rats, as well as to increase glucose tolerance, to decrease the pool of serum and liver lipids and to improve distribution of minerals, thus increasing insulin sensitivity ${ }^{(6)}$.

Sparse studies on DCQA, particularly on their 1,5(cynarine), 3,4-, 3,5- and 4,5-isomers, point to their antimutagenic, anti-inflammatory, hypocholesterolaemic and hepatoprotective activity ${ }^{(7)}$. Some studies also indicate their antiviral activity, with the highest one ascribed to $1,3-$ DCQA $^{(8)}$.

The present study was aimed at identifying the physiological effects of the coupled action of metabolites of endogenous digestion of a dietary fibre fraction and polyphenols from chicory. The following hypothesis was advanced: the dietary concomitant occurrence of prebiotic fructans and different phenolic compounds originating from chicory roots, seeds and leaves may further influence caecal physiology, antioxidant status and lipoprotein profile in rats.

\section{Materials and methods}

\section{Chicory preparations}

Raw chicory (Cichorium intybus L.) was provided by Cykoria Company (Wierzchosławice, Poland), a company specialised in its processing. Preparation was carried out as previously reported ${ }^{(9)}$. Briefly, after drying at $<70^{\circ} \mathrm{C}$, the root cubes $(2 \mathrm{~kg})$, peel $(2.5 \mathrm{~kg})$, leaves $(1.3 \mathrm{~kg})$ and seeds ( $1 \mathrm{~kg}$ ) were extracted with $75 \%$ ethanol. Dried roots and peel were extracted once for $3 \mathrm{~h}$ in a continuous manner, while leaves and seeds were extracted consecutively (four times), with a sample-to-solvent ratio of 1:3. The total volume of ethanol used for obtaining the root and peel extracts was 18 and 20 litres, respectively. The extraction procedure was performed in hermetic containers and without light access from outside. The ethanol was removed by vacuum distillation and the extracts were further freeze-dried for $24 \mathrm{~h}$ beginning at $-30^{\circ} \mathrm{C}$, followed by an additional drying at $40^{\circ} \mathrm{C}$ for $2 \mathrm{~h}$. The final extraction yields (defined as the mass of extract per unit mass of sample) were $33.0 \%$ from roots, $17 \cdot 6 \%$ from peel, $10.0 \%$ from leaves and $3.5 \%$ from seeds. The composition of the extracts is given in Table 1 .

\section{Chemical analyses of the plant material}

DM, ash, protein and fat contents in the chicory extracts were determined according to the official method of Association of Official Analytic Chemists nos 934.01, 940.26, 920.152 and 930.09, respectively ${ }^{(10)}$.

Carbohydrate determinations were performed using HPLC (Knauer Smartline with an RI K-2301 Knauer detector (Berlin, Germany), an Animex HPX 87C $(300 \times 7.8 \mathrm{~mm})$ column and water as a mobile phase (flow rate, $0.5 \mathrm{ml} / \mathrm{min}$; temperature, $\left.85^{\circ} \mathrm{C}\right)$ ). A sample of the tested preparation $(0 \cdot 5-1 \mathrm{~g})$ was dissolved in water $(10 \mathrm{ml})$ and passed through a column filled with a mixture of cation and anion exchangers (a 1:2 ratio). The first $5 \mathrm{ml}$ of the filtrate were rejected and the next $4 \mathrm{ml}$ were collected.

Table 1. Composition of lyophilised chicory preparations used as dietary components

(Mean values and standard deviations, $n 3$ )

\begin{tabular}{|c|c|c|c|c|c|c|c|c|}
\hline \multirow[b]{3}{*}{ Composition (g/100 g) } & \multicolumn{8}{|c|}{ Chicory preparation (extract) } \\
\hline & \multicolumn{2}{|c|}{ Root } & \multicolumn{2}{|c|}{ Peel } & \multicolumn{2}{|c|}{ Seed } & \multicolumn{2}{|c|}{ Leaf } \\
\hline & Mean & SD & Mean & SD & Mean & SD & Mean & SD \\
\hline DM & $97 \cdot 28$ & 0.11 & 98.01 & 0.20 & 95.02 & 0.20 & 97.91 & 0.12 \\
\hline Ash & 3.81 & 0.03 & 8.24 & 0.04 & 8.42 & 0.05 & 6.63 & 0.06 \\
\hline Protein & 5.62 & 0.12 & 8.91 & 0.22 & $10 \cdot 71$ & 0.31 & $8 \cdot 74$ & 0.20 \\
\hline Fat & 1.73 & 0.06 & 0.66 & 0.07 & 14.41 & 0.22 & 1.42 & 0.06 \\
\hline $\begin{array}{l}\text { Monosaccharides and } \\
\text { disaccharides }\end{array}$ & $24 \cdot 33$ & 0.15 & $25 \cdot 61$ & 0.22 & 34.92 & 0.30 & $62 \cdot 41$ & 0.61 \\
\hline Glucose & $2 \cdot 71$ & 0.02 & $3 \cdot 40$ & 0.03 & $12 \cdot 11$ & 0.12 & $27 \cdot 90$ & 0.33 \\
\hline Fructose & 5.72 & 0.03 & $6 \cdot 41$ & 0.04 & 21.41 & 0.21 & $22 \cdot 31$ & 0.32 \\
\hline Sucrose & $15 \cdot 90$ & 0.11 & $15 \cdot 80$ & 0.14 & 1.40 & 0.02 & $12 \cdot 20$ & 0.11 \\
\hline Fructan fraction & $60 \cdot 10$ & 0.32 & $46 \cdot 84$ & 0.22 & 1.71 & 0.04 & $3 \cdot 20$ & 0.02 \\
\hline DP 3-10 (oligofructose) & $46 \cdot 00$ & 0.22 & 33.82 & 0.12 & 1.50 & 0.02 & $3 \cdot 20$ & 0.02 \\
\hline DP $>10$ (inulin) & $14 \cdot 10$ & 0.14 & 13.02 & 0.11 & 0.31 & 0.02 & - & - \\
\hline Phenolic fraction & 0.50 & 0.02 & 1.70 & 0.02 & $9 \cdot 60$ & 0.03 & 4.22 & 0.07 \\
\hline CQA & 0.50 & 0.02 & $1 \cdot 70$ & 0.02 & $9 \cdot 60$ & 0.03 & 1.35 & 0.03 \\
\hline MonoCQA & 0.30 & 0.01 & 0.95 & 0.01 & $2 \cdot 80$ & 0.01 & 1.27 & 0.01 \\
\hline DiCQA & 0.20 & 0.01 & 0.75 & 0.01 & $6 \cdot 80$ & 0.02 & 0.08 & 0.02 \\
\hline Chicoric acid & - & - & - & - & - & - & $2 \cdot 13$ & 0.03 \\
\hline Polyphenolic glycosides & - & - & - & - & - & - & 0.74 & 0.02 \\
\hline
\end{tabular}

$\mathrm{DP}$, degree of polymerisation; CQA, caffeoylquinic acids. 
Of these, $2 \mathrm{ml}$ were used directly for the analysis of monosaccharides and disaccharides. The remaining $2 \mathrm{ml}$ were diluted twice and used for the determination of fructooligosaccharides, after previous desalting and mixing with acetonitrile (a 1:1 ratio) according to the procedure of Król \& Grzelak ${ }^{(11)}$.

Phenolic determinations were performed, according to the procedure of Milala et al. ${ }^{(9)}$, using HPLC (a Dionex system with a diode array detector (Germering, Germany), coupled with a $4 \mu \mathrm{m}$ Fusion-RP 80A column $(150 \times 2.0 \mathrm{~mm}$; Phenomenex Synergi, Torrance, CA, USA)). The elution solvents were A $(0.05 \%$ phosphoric acid in water $)$ and $\mathrm{B}$ $(0.05 \%$ phosphoric acid in acetonitrile). A flow rate of $0.25 \mathrm{ml} / \mathrm{min}$ and a temperature of $25^{\circ} \mathrm{C}$ were set as the operating conditions. For the linear gradient method, the program started with $4-50 \% \mathrm{~B}$ from 0 to $33 \mathrm{~min}, 50 \% \mathrm{~B}$ from 33 to $34 \mathrm{~min}, 4 \% \mathrm{~B}$ from 34 to $35 \mathrm{~min}$ and a post-run with $4 \% \mathrm{~B}$ for $10 \mathrm{~min}$ to equilibrate the column for the next injection. The absorbance was measured at 325 and $360 \mathrm{~nm}$. Hyperoside, quercetin glucoside, apigenin and luteolin were purchased from Extrasynthese (ZI Lyon Nord, Genay, France). Chicoric acid (dicaffeoyltartaric acid) was isolated from the leaves as described elsewhere $^{(12)}$, and its purity was confirmed by UV spectroscopy, optical rotation and HPLC. DCQA was a pure substance isolated by semi-preparative HPLC (column, $250 \times 10 \mathrm{~mm}$ (Phenomenex); volume of injection, $200 \mu \mathrm{l}$; flow rate, $5 \mathrm{ml} / \mathrm{min}$; eluent as above) from the root extracts and was confirmed by the MS spectrum (fast atom bombardmentMS $[\mathrm{M}-\mathrm{H}]^{-}, 515 \cdot 3$; MAT95 mass spectrometer, Finnigan MAT GmbH, Bremen, Germany). Quercetin glucuronide was isolated from the leaf extract by semi-preparative HPLC and was confirmed by UV and MS spectra (column, $250 \times 10 \mathrm{~mm}$ (Phenomenex); injection volume, $200 \mu \mathrm{l}$; flow rate, $5 \mathrm{ml} / \mathrm{min}$; eluent as above). All aforementioned substances were used as identification standards by comparison of retention times and UV spectra, and additionally by comparision with the data obtained previously ${ }^{(13,14)}$. All hydroxycinnamic acids were calculated as chlorogenic acid (3-caffeoylquinic acid (CQA)) and all polyphenolic glycosides as quercetin glucuronide (Sigma, St Louis, MO, USA).

\section{Animal study}

The animal protocol used in the present study was approved by the Local Institutional Animal Care and Use Committee. The assessment was conducted on forty male Wistar rats aged $35 \mathrm{~d}$ and weighing $103 \cdot 1$ (SD 4.25) g, and are divided into five groups of eight animals each. All animals were housed individually over 4 weeks in metabolism cages with free access to water and semi-purified casein diets (Table 2). The selection of the rats and their maintenance over the $28 \mathrm{~d}$ experiment followed the common regulations. The environment was controlled with a $12 \mathrm{~h}$ light $-12 \mathrm{~h}$ dark cycle, a temperature of $21 \pm 1^{\circ} \mathrm{C}$, a relative humidity of 50 (SD 5)\% and twenty air changes $/ \mathrm{h}$.
All experimental diets were similar in terms of dietary ingredients except for the phenolic fraction, and especially the CQA thereof. The diets were adjusted to the level of carbohydrates and the degree of polymerisation of fructans with the calculated amounts of phenolics. The adjustment of fructans was performed using commercial preparations: Frutafit $^{\circledR}$ TEX! with degree of polymerisation $>10$ (Sensus, Roosendaal, The Netherlands) and Raftilose ${ }^{\circledR}$ P95 with degree of polymerisation 3-7 (Orafti, Oreye, Belgium). The control diet contained no phenolics. A diet supplemented with $10 \%$ of the root extract (the PL diet) contained $0.05 \%$ of CQA (MCQA:DCQA, 60:40), a diet supplemented with $6.5 \%$ of the peel extract (the PM diet) contained $0 \cdot 107 \%$ of CQA (MCQA:DCQA, 54:46), a diet supplemented with $8 \%$ of the peel extract and $0.8 \%$ of the seed extract (the $\mathrm{PH}$ diet) contained $0 \cdot 208 \%$ of CQA (MCQA:DCQA, 45:55) and a diet supplemented with $2.5 \%$ of the leaf extract (the PMc diet) with $0.106 \%$ of the total phenolics. The percentage composition of the phenolic fraction in the PMc diet was as follows: MCQA:DCQA:chicoric acid:quercetin glucuronide, 30:2: 50:18. In all experimental diets, the extracts were added at the expense of sucrose, fructans and maize starch.

During the study, the rats were subjected to $\mathrm{N}$ balance that was preceded by a $10 \mathrm{~d}$ preliminary period. In the $5 \mathrm{~d}$ period of the proper experiment, faeces and urine were thoroughly collected from all the rats that were kept in balance cages (Tecniplast Spa, Buguggiate, Italy). The content of total $\mathrm{N}$ in the diets, faeces and urine collected in the balance period was assayed using the Kjeldahl method.

The experimental groups were additionally monitored for body-weight gains and diet intake, which enabled the calculation of the feed conversion ratio. Faecal $\mathrm{pH}$ was measured using a microelectrode and a $\mathrm{pH} /$ ion meter (model 301; Hanna Instruments, Vila do Conde, Portugal) after the first, second, third and fourth week of experimental feeding. At the termination of the experiment, the rats were anaesthetised with sodium pentobarbital according to the recommendations for euthanasia of experimental animals. After laparotomy, blood samples were taken from the caudal vena cava, and then small intestine, caecum, colon, liver, heart, kidneys and lungs were removed and weighed. The small intestine was divided into four equal parts, and the second part (jejunum) from the stomach side was rinsed with ice-cold physiological saline and cut open. The mucosal samples were collected by scraping with glass slides on an iced glass plate, weighed and subsequently stored at $-40^{\circ} \mathrm{C}$. Disaccharidase (sucrase, maltase and lactase) activity was assayed using the method of Messer \& Dahlqvist ${ }^{(15)}$ with modifications. The amount of liberated glucose was measured spectrophotometrically and the enzyme activity was expressed as $\mu \mathrm{mol}$ disaccharide hydrolysed/min per $\mathrm{g}$ of protein. Samples of caecal contents were used for immediate analysis $\left(\mathrm{NH}_{3}, \mathrm{DM}\right.$ and SCFA), while the rest 
Table 2. Composition of the diets

\begin{tabular}{|c|c|c|c|c|c|}
\hline \multirow[b]{2}{*}{ Composition (g/100 g) } & \multicolumn{5}{|c|}{ Diet } \\
\hline & $\mathrm{C}$ & PL & PM & $\mathrm{PH}$ & PMc \\
\hline Casein* & $14 \cdot 80$ & 14.80 & 14.80 & 14.80 & $14 \cdot 80$ \\
\hline DL-Met & 0.20 & 0.20 & 0.20 & 0.20 & 0.20 \\
\hline Soyabean oilt & 8.00 & 8.00 & 8.00 & 8.00 & 8.00 \\
\hline Cholesterolł & 0.50 & 0.50 & 0.50 & 0.50 & 0.50 \\
\hline Mineral mix§ & 3.50 & 3.50 & 3.50 & 3.50 & 3.50 \\
\hline Vitamin mix\| & 1.00 & 1.00 & 1.00 & 1.00 & 1.00 \\
\hline Chicory root extract & - & $10 \cdot 00$ & - & - & - \\
\hline Chicory peel extract & - & - & $6 \cdot 50$ & 8.00 & - \\
\hline Chicory seed extract & - & - & - & 0.80 & - \\
\hline Chicory leaf extract & - & - & - & - & 2.50 \\
\hline Oligofructose with DP 3-7 (Raftilose ${ }^{\circledR}$ P95) & 4.63 & - & 2.45 & 1.8 & 4.55 \\
\hline Inulin with DP $>10$ (Frutafit ${ }^{\circledR}$ TEX!) & 1.38 & - & 0.53 & 0.34 & 1.38 \\
\hline Sucrose & $2 \cdot 40$ & - & 0.80 & - & 0.90 \\
\hline Maize starch & 63.59 & $62 \cdot 0$ & $61 \cdot 72$ & 61.06 & $62 \cdot 67$ \\
\hline \multicolumn{6}{|l|}{ Calculated content of selected fractions } \\
\hline Monosaccharides and disaccharides (\% of diet) & 2.40 & 2.43 & 2.46 & 2.32 & 2.46 \\
\hline Fructan fraction (\% of diet) & $6 \cdot 01$ & 6.01 & 6.01 & 6.01 & 6.01 \\
\hline FOS with DP $3-10$ (\% of fraction) & $77 \cdot 00$ & 77.00 & 77.00 & 77.00 & $77 \cdot 00$ \\
\hline Fructans with DP $>10$ (\% of fraction) & 23.00 & 23.00 & 23.00 & 23.00 & 23.00 \\
\hline Phenolic fraction (\% of diet) & - & 0.050 & 0.107 & 0.208 & 0.106 \\
\hline MCQA (\% of fraction) & - & $60 \cdot 00$ & 54.00 & 45.00 & $30 \cdot 00$ \\
\hline DCQA (\% of fraction) & - & $40 \cdot 00$ & 46.00 & $55 \cdot 00$ & 2.00 \\
\hline Chicoric acid (\% of fraction) & _- & - & - & - & $50 \cdot 00$ \\
\hline Phenolic glycosides (\% of fraction) & - & - & - & - & 18.00 \\
\hline \multirow{4}{*}{\multicolumn{6}{|c|}{ 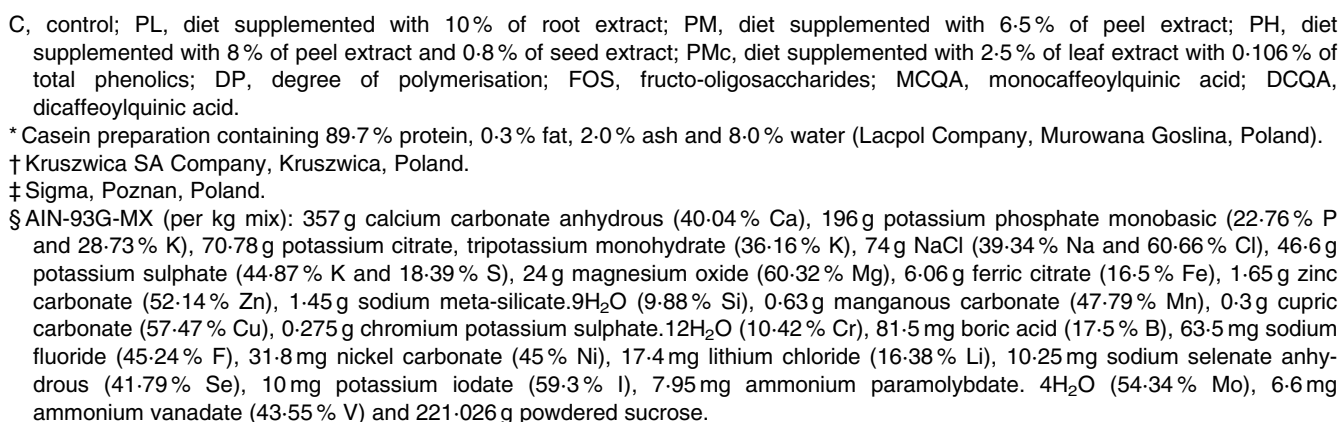 }} \\
\hline & & & & & \\
\hline & & & & & \\
\hline & & & & & \\
\hline \multicolumn{6}{|c|}{ 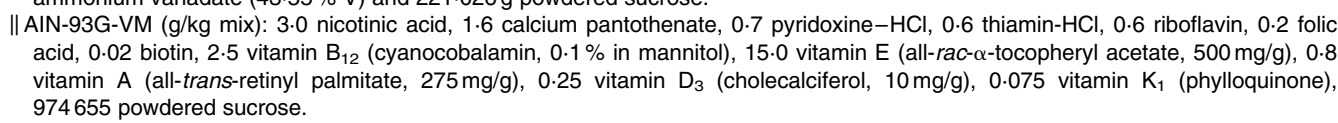 } \\
\hline
\end{tabular}

of the caecal digesta was transferred to tubes and stored at $-70^{\circ} \mathrm{C}$. From the fresh caecal digesta, $\mathrm{NH}_{3}$ was extracted, trapped in a solution of boric acid in Conway's dishes and determined by direct titration with $\mathrm{H}_{2} \mathrm{SO}_{4}$. The DM of the digesta was determined at $105^{\circ} \mathrm{C}$.

Caecal digesta samples were subjected to SCFA analysis, using GC (Shimadzu GC-2010, Kyoto, Japan). The samples $(0.2 \mathrm{~g})$ were mixed with $0.2 \mathrm{ml}$ formic acid, diluted with deionised water and centrifuged at $7211 \mathrm{~g}$ for $10 \mathrm{~min}$. The supernatant was loaded onto a capillary column (SGE $\mathrm{BP} 21,30 \mathrm{~m} \times 0.53 \mathrm{~mm}$ ) using an on-column injector. The initial oven temperature was $85^{\circ} \mathrm{C}$ and was raised to $180^{\circ} \mathrm{C}$ by $8^{\circ} \mathrm{C} / \mathrm{min}$ and held there for $3 \mathrm{~min}$. The temperatures of the flame ionisation detector and the injection port were 180 and $85^{\circ} \mathrm{C}$, respectively. The sample volume for GC analysis was $1 \mu$ l. The caecal SCFA pool size was calculated as the sum of the SCFA concentration in the digesta and caecal digesta mass.
The activity of bacterial enzymes ( $\beta$-glucosidase and $\beta$-glucuronidase) released into the environment was measured by the rate of $p$ - or $o$-nitrophenol release from their nitrophenylglucosides, according to the method described elsewhere ${ }^{(16)}$, in fresh faeces, which were taken after each week of the experiment, and in the caecal digesta on termination of the experiment $(\alpha-$ and $\beta$-glucosidase, $\alpha$ - and $\beta$-galactosidase and $\beta$-glucuronidase). The following substrates were used: $p$-nitrophenyl$\alpha$-D-glucopyranoside (for $\alpha$-glucosidase); $p$-nitrophenyl- $\beta$ D-glucopyranoside (for $\beta$-glucosidase); $p$-nitrophenyl- $\alpha$ D-galactopyranoside ( $\alpha$-galactosidase); o-nitrophenyl- $\beta$-Dgalactopyranoside ( $\beta$-galactosidase); $p$-nitrophenyl- $\beta$-Dglucuronide (for $\beta$-glucuronidase). The reaction mixture contained $0.3 \mathrm{ml}$ of a substrate solution $(5 \mathrm{~mm})$ and $0.2 \mathrm{ml}$ of a $1: 10(\mathrm{v} / \mathrm{v})$ dilution of the caecal/faecal sample in $100 \mathrm{~mm}$ phosphate buffer ( $\mathrm{pH} 7 \cdot 0$ ) after centrifugation at $7211 \mathrm{~g}$ for $15 \mathrm{~min}$. Incubation was carried out at $37^{\circ} \mathrm{C}$ and 
p-nitrophenol was quantified at 400 and $420 \mathrm{~nm}$ (o-nitrophenol concentration) after the addition of $2.5 \mathrm{ml}$ of $0.25 \mathrm{~m}$-cold sodium carbonate. The enzymatic activity ( $\alpha$ - and $\beta$-glucosidase, $\alpha$ - and $\beta$-galactosidase and $\beta$ glucuronidase) was expressed as $\mu \mathrm{mol}$ product formed/ $\mathrm{h}$ per $\mathrm{g}$ of digesta.

The extent of lipid peroxidation in selected tissues (kidneys, lungs, liver and heart) and in the serum was measured by quantifying malondialdehyde formed in terms of thiobarbituric acid-reactive substances (TBARS $^{(17)}$. Serum concentrations of TAG, total cholesterol and its HDL fraction were estimated with reagents from Alpha Diagnostics Limited (Warsaw, Poland). The activity of glutathione peroxidase in the heparinised blood and superoxide dismutase in the erythrocyte lysate were determined using reagents from Randox Laboratories Limited (Crumlin, Antrim, UK). The serum antioxidant capacity of water-soluble (ACW) and the antioxidant capacity of lipid-soluble (ACL) substances (kit; Analytik Jena AG, Jena, Germany) were determined by a photochemiluminescence detection method, using a Photochem (Analytik Jena AG). In the photochemiluminescence assay, the generation of free radicals was partially eliminated by the reaction with antioxidants present in the serum samples, and the remaining radicals were quantified by luminescence generation. Ascorbate and Trolox calibration curves were used in order to evaluate ACW and ACL, respectively, and the results were expressed as $\mu \mathrm{mol}$ ascorbate or Trolox equivalents/ml serum.

\section{Statistical analyses}

Results were analysed statistically using one-way ANOVA, and the significance of differences between groups was determined using Duncan's multiple-range test at a significance level of $P \leq 0.05$. Data are expressed as means and standard deviations. Calculations were made with STATISTICA 8.0 (StatSoft Corporation, Kraków, Poland).

\section{Results}

The presence of the polyphenolic fraction in the experimental diets had no effect on the faecal $\mathrm{pH}$ value measured after the first and second week of the experiment (Table 3). The faecal $\mathrm{pH}$ value of rats measured on days 21 and 28 of the experiment was significantly higher in the PMc group than in the control (C), PL and PM groups. The activity of faecal $\beta$-glucosidase released into the environment on day 21 of the experiment turned out to be significantly lower in the PM and PMc groups compared with the $\mathrm{C}$ group. After 4 weeks of feeding with the experimental diets, faecal $\beta$-glucosidase activity in the $\mathrm{C}$ and PL groups was significantly higher than in the other groups. Diet supplementation with the preparations examined did not result in any significant differences in faecal $\beta$-glucuronidase activity on day 7 of experimental feeding, while on day 14, its activity in the PMc group was significantly higher than in the faeces of rats fed the PM and $\mathrm{PH}$ diets. No significant differences were observed between the $\mathrm{C}$ group and the experimental groups in the second week

Table 3. Faecal $\mathrm{pH}$ value and bacterial $\beta$-glucosidase and $\beta$-glucuronidase activity in rats fed the diets supplemented with the chicory extracts*

(Mean values and standard deviations)

\begin{tabular}{|c|c|c|c|c|c|c|c|c|c|c|}
\hline & \multicolumn{2}{|c|}{ C } & \multicolumn{2}{|c|}{$\mathrm{PL}$} & \multicolumn{2}{|c|}{ PM } & \multicolumn{2}{|c|}{$\mathrm{PH}$} & \multicolumn{2}{|c|}{ PMc } \\
\hline & Mean & SD & Mean & SD & Mean & SD & Mean & SD & Mean & SD \\
\hline \multicolumn{11}{|l|}{ Faecal pH } \\
\hline Day 0 & $6 \cdot 86$ & 0.25 & $6 \cdot 88$ & 0.28 & $6 \cdot 86$ & 0.24 & $6 \cdot 84$ & 0.25 & $6 \cdot 87$ & 0.30 \\
\hline After $7 d$ & $6 \cdot 14$ & $0 \cdot 17$ & $6 \cdot 12$ & 0.05 & $6 \cdot 10$ & $0 \cdot 12$ & $6 \cdot 14$ & $0 \cdot 10$ & $6 \cdot 18$ & $0 \cdot 16$ \\
\hline After $14 \mathrm{~d}$ & 5.97 & 0.09 & 6.05 & 0.12 & 5.95 & 0.12 & 6.04 & 0.08 & $6 \cdot 11$ & 0.28 \\
\hline After $21 \mathrm{~d}$ & $5 \cdot 95^{\mathrm{b}}$ & $0 \cdot 19$ & $6 \cdot 06^{\mathrm{b}}$ & 0.07 & $6 \cdot 04^{\mathrm{b}}$ & 0.20 & $6 \cdot 12^{a, b}$ & 0.11 & $6 \cdot 24^{\mathrm{a}}$ & 0.14 \\
\hline After $28 d$ & $6.09^{b}$ & 0.07 & $6 \cdot 15^{b}$ & 0.12 & $6 \cdot 07^{b}$ & 0.29 & $6 \cdot 18^{a, b}$ & 0.13 & $6 \cdot 38^{a}$ & 0.21 \\
\hline \multicolumn{11}{|c|}{$\beta$-Glucosidase ( $\mu \mathrm{mol} / \mathrm{h}$ per $\mathrm{g}$ faeces$)$} \\
\hline Day 0 & $25 \cdot 31$ & 9.93 & 25.42 & $9 \cdot 23$ & $25 \cdot 21$ & $7 \cdot 28$ & $25 \cdot 49$ & $9 \cdot 01$ & $25 \cdot 38$ & $9 \cdot 85$ \\
\hline After $7 d$ & 26.46 & $2 \cdot 89$ & $21 \cdot 18$ & $9 \cdot 11$ & $22 \cdot 51$ & $10 \cdot 77$ & 24.04 & 2.65 & $21 \cdot 22$ & 2.94 \\
\hline After $14 d$ & $23 \cdot 61$ & 2.69 & $22 \cdot 66$ & 2.45 & 17.69 & $13 \cdot 14$ & 23.57 & $5 \cdot 62$ & $21 \cdot 60$ & $6 \cdot 37$ \\
\hline After $21 \mathrm{~d}$ & $21 \cdot 60^{\mathrm{a}}$ & $6 \cdot 24$ & $20 \cdot 01^{a, b}$ & $7 \cdot 17$ & $13 \cdot 64^{\mathrm{b}}$ & 1.74 & $16 \cdot 82^{\mathrm{a}, \mathrm{b}}$ & $6 \cdot 18$ & $12 \cdot 79^{\mathrm{b}}$ & 5.51 \\
\hline After $28 d$ & $18 \cdot 88^{\mathrm{a}}$ & $3 \cdot 70$ & $17 \cdot 84^{a}$ & $2 \cdot 83$ & $11 \cdot 71^{\mathrm{b}}$ & 3.35 & $12 \cdot 51^{b}$ & 4.48 & $11 \cdot 10^{\mathrm{b}}$ & $3 \cdot 15$ \\
\hline \multicolumn{11}{|c|}{$\beta$-Glucuronidase ( $\mu \mathrm{mol} / \mathrm{h}$ per $\mathrm{g}$ faeces) } \\
\hline Day 0 & $32 \cdot 80$ & $16 \cdot 17$ & $32 \cdot 71$ & $14 \cdot 16$ & 32.58 & $12 \cdot 41$ & 32.77 & $13 \cdot 82$ & 32.79 & 14.74 \\
\hline After $7 \mathrm{~d}$ & $26 \cdot 10$ & $4 \cdot 30$ & 27.54 & 4.92 & $22 \cdot 11$ & 6.04 & 23.62 & 4.07 & 27.88 & $5 \cdot 33$ \\
\hline After $14 \mathrm{~d}$ & $23 \cdot 80^{a, b}$ & 1.54 & $25 \cdot 61^{a, b}$ & $10 \cdot 38$ & $19 \cdot 34^{\mathrm{b}}$ & 7.96 & $17 \cdot 41^{\mathrm{b}}$ & $2 \cdot 26$ & $27 \cdot 13^{a}$ & 8.51 \\
\hline After $21 \mathrm{~d}$ & $25 \cdot 28^{a}$ & $5 \cdot 34$ & $22 \cdot 29^{a, b}$ & 5.05 & $18 \cdot 48^{\mathrm{b}}$ & 5.45 & $16 \cdot 60^{\mathrm{b}}$ & 3.76 & $20 \cdot 34^{a, b}$ & 5.46 \\
\hline After $28 d$ & $24 \cdot 01^{a}$ & $10 \cdot 20$ & $23 \cdot 44^{\mathrm{a}, \mathrm{b}}$ & 4.87 & $16 \cdot 90^{\mathrm{b}}$ & $14 \cdot 12$ & $14.52^{\mathrm{b}}$ & 1.80 & $18 \cdot 88^{\mathrm{a}, \mathrm{b}}$ & $6 \cdot 60$ \\
\hline
\end{tabular}

C, control; PL, diet supplemented with $10 \%$ of root extract; PM, diet supplemented with $6.5 \%$ of peel extract; $\mathrm{PH}$, diet supplemented with $8 \%$ of peel extract and $0.8 \%$ of seed extract; PMc, diet supplemented with $2.5 \%$ of leaf extract with $0.106 \%$ of total phenolics.

${ }^{a, b}$ Mean values within a row with unlike superscript letters were significantly different $(P \leq 0.05)$.

* Experimental factor in particular groups: PL, contained $10 \%$ of chicory root extract; PM, contained $6.5 \%$ of a chicory peel extract; $\mathrm{PH}$, contained $8 \%$ of a chicory root peel extract and $0.8 \%$ of a chicory seed extract; PMc, contained $2.5 \%$ of a chicory leaf extract. The content of dietary polyphenols in the experimental groups was as follows: C, 0\%; PL, 0.050\%; PM, 0.107\%; PH, 0.208\%; PMc, 0.106\%. 
of the experiment. In turn, after 3 and 4 weeks of the study, faecal $\beta$-glucuronidase activity was highest in the $C$ group and differed significantly from the value determined in the PM and PH groups.

The chicory preparations applied in the study had no significant effect on the body-weight gains of rats, diet intake and feed conversion ratio (Table 4). The rats fed the diet with the highest content of polyphenols (the PH group) excreted the highest quantity of faecal $\mathrm{N}$ within $5 \mathrm{~d}$ of the balance study, with the quantity being significantly higher than that recorded in the $\mathrm{C}$ group. When losses of $\mathrm{N}$ with faeces were expressed in percentage of ingested $\mathrm{N}$, no differences were observed between the $\mathrm{C}$ group and the experimental groups, while the value of that parameter was significantly higher in the PMc group compared with the PM group. For this reason, the value of $\mathrm{N}$ apparent digestibility index differed significantly only between the PM and PMc groups (PM $>$ PMc; 드 $P \leq 0.05)$. The quantity of $\mathrm{N}$ excreted with urine was significantly lower in the $\mathrm{C}$ and PMc groups than in the other groups. The $\mathrm{N}$ retention index, considering losses of $\mathrm{N}$ both with faeces and urine, did not differ statistically between the groups. The 4-week administration of the
PMc diet to rats evoked a significant increase in the $\mathrm{pH}$ of the small-intestine digesta and in the mucosal sucrase activity compared with the $\mathrm{C}$ diet. The highest level of diet supplementation with the polyphenolic compounds of chicory (the PH diet) significantly increased the mass of both the caecal wall and digesta $(P \leq 0.05 v$. C group) The caecal digesta of the PH group was also characterised by the lowest DM concentration $(P \leq 0.05 v$. PMc).

The experimental diets applied in the discussed experiment did not have any significant effect on the activities of the examined intestinal microbiota enzymes released into the caecal environment, except for the activity of $\beta$ glucuronidase (Table 5). Its activity diminished significantly in the PH group ( $P \leq 0.05 v$. C group). In the PH and PMc groups, a tendency for an increasing activity of bacterial $\alpha$-galactosidase was observed, with respect to the $\mathrm{C}$ group ( $P=0.062$ and 0.059 , respectively). The experimental treatments did not affect the concentration of the total SCFA in the caecal digesta. The concentrations of individual fatty acids were the same in all groups, yet the highest level of polyphenols in the $\mathrm{PH}$ diet caused a significant decrease in the concentration of propionic acid in the $\mathrm{PH}$ group compared with the $\mathrm{C}$ group $(P \leq 0.05)$. When

Table 4. Body weight, diet intake, nitrogen excretion patterns and gastrointestinal tract parameters in rats fed the experimental diets (Mean values and standard deviations)

\begin{tabular}{|c|c|c|c|c|c|c|c|c|c|c|}
\hline & \multicolumn{2}{|c|}{$\mathrm{C}$} & \multicolumn{2}{|c|}{ PL } & \multicolumn{2}{|c|}{ PM } & \multicolumn{2}{|c|}{$\mathrm{PH}$} & \multicolumn{2}{|c|}{ PMc } \\
\hline & Mean & SD & Mean & SD & Mean & SD & Mean & SD & Mean & SD \\
\hline Initial BW (g) & $103 \cdot 1$ & $2 \cdot 7$ & $103 \cdot 2$ & 3.5 & $103 \cdot 2$ & $5 \cdot 5$ & $103 \cdot 1$ & $2 \cdot 4$ & $103 \cdot 1$ & 4.5 \\
\hline Final BW (g) & 228.5 & $15 \cdot 7$ & $224 \cdot 6$ & $19 \cdot 1$ & $229 \cdot 6$ & 6.9 & $227 \cdot 4$ & $8 \cdot 8$ & $224 \cdot 2$ & $9 \cdot 0$ \\
\hline BW gain $(g)$ & $125 \cdot 3$ & $17 \cdot 4$ & $121 \cdot 4$ & $18 \cdot 9$ & $126 \cdot 4$ & $7 \cdot 3$ & $124 \cdot 4$ & $10 \cdot 3$ & $121 \cdot 1$ & $10 \cdot 0$ \\
\hline Diet intake (g) & $355 \cdot 0$ & $27 \cdot 3$ & 347.4 & 43.9 & 354.7 & $15 \cdot 5$ & $356 \cdot 0$ & $11 \cdot 0$ & $351 \cdot 3$ & $29 \cdot 6$ \\
\hline FCR $(g / g)$ & $2 \cdot 86$ & 0.20 & 2.88 & 0.24 & $2 \cdot 81$ & 0.13 & 2.88 & 0.22 & 2.90 & 0.07 \\
\hline$N$ intake $(g / 5 d)$ & $1 \cdot 38$ & 0.07 & 1.42 & 0.18 & 1.46 & 0.07 & 1.40 & 0.09 & $1 \cdot 34$ & 0.04 \\
\hline $\mathrm{N}$ in faeces $(\mathrm{g})$ & $0.23^{b}$ & 0.00 & $0.24^{a, b}$ & 0.00 & $0.24^{a, b}$ & 0.01 & $0.25^{a}$ & 0.01 & $0 \cdot 24^{a, b}$ & 0.00 \\
\hline $\mathrm{N}$ faecal (\% N intake) & $16 \cdot 86^{a, b}$ & $1 \cdot 20$ & $16 \cdot 78^{a, b}$ & 2.06 & $16 \cdot 39^{b}$ & 0.85 & $17 \cdot 66^{a, b}$ & $1 \cdot 11$ & $18 \cdot 13^{a}$ & 0.68 \\
\hline $\mathrm{N}$ in urine $(\mathrm{g})$ & $0.43^{\mathrm{b}}$ & 0.02 & $0.49^{a}$ & 0.00 & $0.49^{a}$ & 0.02 & $0.48^{\mathrm{a}}$ & 0.04 & $0.42^{\mathrm{b}}$ & 0.02 \\
\hline $\mathrm{N}$ urinary (\% $\mathrm{N}$ intake) & $31 \cdot 33$ & $2 \cdot 28$ & 34.56 & 4.08 & $33 \cdot 13$ & 2.07 & $34 \cdot 10$ & $4 \cdot 28$ & 31.42 & 1.65 \\
\hline N digestibility (\%) & $83 \cdot 14^{a, b}$ & $1 \cdot 20$ & $83 \cdot 22^{a, b}$ & 2.06 & $83 \cdot 61^{a}$ & 0.85 & $82 \cdot 34^{a, b}$ & $1 \cdot 11$ & $81 \cdot 87^{b}$ & 0.68 \\
\hline $\mathrm{N}$ utilisation (\%) & $51 \cdot 81$ & $3 \cdot 28$ & 48.66 & 6.09 & $50 \cdot 48$ & $2 \cdot 23$ & $48 \cdot 24$ & $4 \cdot 85$ & $50 \cdot 45$ & 1.65 \\
\hline \multicolumn{11}{|l|}{ Stomach } \\
\hline $\mathrm{pH}$ of digesta & $3 \cdot 21$ & 0.62 & 3.53 & 0.39 & 3.44 & 0.74 & $3 \cdot 25$ & 0.69 & $3 \cdot 60$ & 0.62 \\
\hline \multicolumn{11}{|l|}{ Small intestine } \\
\hline Full mass (g/100 g BW) & 3.06 & 0.30 & 2.91 & 0.36 & 3.01 & 0.24 & $3 \cdot 23$ & 0.45 & $3 \cdot 22$ & 0.48 \\
\hline $\mathrm{pH}$ of digesta & $6 \cdot 00^{\mathrm{b}}$ & 0.23 & $6 \cdot 19^{a, b}$ & 0.35 & $6 \cdot 14^{a, b}$ & 0.24 & $6 \cdot 10^{a, b}$ & 0.13 & $6 \cdot 87^{a}$ & 0.31 \\
\hline \multicolumn{11}{|l|}{ Mucosal disaccharidase } \\
\hline Sucrase* & $25 \cdot 02^{b}$ & 3.56 & $29 \cdot 66^{a, b}$ & $5 \cdot 93$ & $29 \cdot 68^{a, b}$ & $3 \cdot 34$ & $30 \cdot 90^{a, b}$ & $3 \cdot 36$ & $33 \cdot 43^{\mathrm{a}}$ & $6 \cdot 24$ \\
\hline Maltase* & $89 \cdot 78$ & $8 \cdot 26$ & $80 \cdot 41$ & $4 \cdot 21$ & $82 \cdot 34$ & $5 \cdot 28$ & $82 \cdot 60$ & $2 \cdot 75$ & $82 \cdot 87$ & $5 \cdot 80$ \\
\hline Lactase* $^{\star}$ & $12 \cdot 22$ & $3 \cdot 31$ & 14.56 & 3.05 & 14.59 & 2.65 & $12 \cdot 54$ & $1 \cdot 20$ & $14 \cdot 61$ & 3.04 \\
\hline \multicolumn{11}{|l|}{ Caecum } \\
\hline Tissue (g/100 g BW) & $0.48^{\mathrm{b}}$ & 0.09 & $0 \cdot 61^{a, b}$ & 0.14 & $0.60^{a, b}$ & 0.12 & $0.63^{a}$ & 0.17 & $0.51^{a, b}$ & 0.07 \\
\hline Digesta (g/100 g BW) & $1 \cdot 80^{\mathrm{b}}$ & 0.56 & $1.90^{a, b}$ & 0.44 & $2 \cdot 31^{a, b}$ & 0.98 & $2 \cdot 76^{\mathrm{a}}$ & $1 \cdot 20$ & $2 \cdot 03^{a, b}$ & 0.51 \\
\hline $\mathrm{pH}$ of digesta & $6 \cdot 10$ & 0.43 & $5 \cdot 88$ & 0.55 & $5 \cdot 94$ & 0.42 & $5 \cdot 87$ & 0.28 & $6 \cdot 18$ & 0.32 \\
\hline $\mathrm{DM}(\%)$ & $19 \cdot 15^{a, b}$ & 2.48 & $18 \cdot 50^{a, b}$ & $2 \cdot 24$ & $19 \cdot 47^{a, b}$ & $2 \cdot 19$ & $17 \cdot 84^{b}$ & 3.04 & $20 \cdot 73^{a}$ & 1.03 \\
\hline $\mathrm{NH}_{3}(\mathrm{mg} / \mathrm{g})$ & 0.33 & 0.03 & 0.32 & 0.02 & 0.39 & 0.03 & 0.40 & 0.08 & 0.38 & 0.16 \\
\hline \multicolumn{11}{|l|}{ Colon } \\
\hline Tissue (g/100 g BW) & 0.53 & 0.04 & 0.52 & 0.06 & 0.53 & 0.05 & 0.56 & 0.03 & 0.54 & 0.03 \\
\hline $\mathrm{pH}$ of digesta & $6 \cdot 30$ & 0.22 & $6 \cdot 35$ & 0.43 & $6 \cdot 32$ & 0.40 & $6 \cdot 26$ & 0.30 & 6.54 & 0.42 \\
\hline
\end{tabular}

C, control; PL, diet supplemented with $10 \%$ of root extract; PM, diet supplemented with $6.5 \%$ of peel extract; PH, diet supplemented with $8 \%$ of peel extract and $0.8 \%$ of seed extract; PMc, diet supplemented with $2.5 \%$ of leaf extract with $0.106 \%$ of total phenolics; BW, body weight; FCR, feed conversion ratio.

a,b Mean values within a row with unlike superscript letters were significantly different $(P \leq 0.05)$.

${ }^{*} \mu \mathrm{mol} / \mathrm{min}$ per $\mathrm{g}$ of protein. 
comparing the $\mathrm{C}$ group with particular experimental groups, no significant differences were determined in the size of the total SCFA pool nor in the pools of individual acids. Only the pools of the total SCFA and acetic acid in the PH group turned out to be significantly higher in comparison with rats fed the PL diet.

Out of all groups assayed, the PM group was characterised by the highest serum ACW and, simultaneously, by the lowest serum ACL values (Table 6). These differences were statistically significant compared with the $\mathrm{C}$ group and in the case of ACL - also compared with the PL group. In the lung tissue of rats administered the $\mathrm{PH}$ and $\mathrm{PMC}$ diets, the concentration of TBARS was significantly lower than that determined in the $\mathrm{C}$ group $(P \leq 0.05)$. Furthermore, the $\mathrm{PH}$ group was characterised by a significantly lower concentration of TBARS in the lung tissue compared with rats fed the PM diet. The serum concentration of total cholesterol was subject to a significant decline in the PMc group with respect to the $\mathrm{PH}$ group, which resulted in significant differences in the HDL-cholesterol/total cholesterol profile between these groups ( $\mathrm{PMc}>\mathrm{PH} ; P \leq 0 \cdot 05)$.

\section{Discussion}

The application of the preparations from whole roots, root peel, seeds and leaves of chicory that diversified the content and composition of the polyphenolic fraction in the diet had no significant effect on either the body weight or the feed conversion ratio. Body-weight gains of the experimental animals have also remained unaffected in toxicological surveys on diet supplementation with an ethanolic extract from chicory roots ${ }^{(18)}$. The results of a large number of studies indicate that polyphenolic compounds, including phenolic acids, exhibit diversified activity in the bodies of humans and animals ${ }^{(1,19,20)}$. In the discussed experiment, significant differences in coefficients of $\mathrm{N}$ digestibility were found only between the PM and PMc groups. This indicates that the high content of chicoric acid and glycosides in the extract from chicory leaves diminished the digestibility of total $\mathrm{N}$ from the diet compared with the root peel extract constituted exclusively by CQA. For other physiological parameters, including $\mathrm{N}$ retention, similar parameters of the small-intestine functioning and the fermentation process in the caecum and the colon did not confirm the aforementioned differences. A tendency could only be observed for restricting the process of intestinal digesta acidification by the polyphenolic fraction of chicory leaves.

Few in vivo experiments show that the pool of chlorogenic and DCQA absorbed in the small intestine affects the functioning of the cardiovascular system and peripheral tissues, whereas that metabolised by microbiota influences

Table 5. Bacterial enzyme activity as well as concentration, pool and profile of SCFA in the caecal digesta (Mean values and standard deviations)

\begin{tabular}{|c|c|c|c|c|c|c|c|c|c|c|}
\hline & \multicolumn{2}{|c|}{$\mathrm{C}$} & \multicolumn{2}{|c|}{ PL } & \multicolumn{2}{|c|}{ PM } & \multicolumn{2}{|c|}{$\mathrm{PH}$} & \multicolumn{2}{|c|}{ PMc } \\
\hline & Mean & SD & Mean & SD & Mean & SD & Mean & SD & Mean & SD \\
\hline \multicolumn{11}{|c|}{ Enzyme activity ( $\mu \mathrm{mol} / \mathrm{h}$ per $\mathrm{g}$ digesta) } \\
\hline$\alpha$-Glucosidase & $27 \cdot 4$ & $16 \cdot 4$ & $26 \cdot 3$ & $14 \cdot 2$ & 27.5 & $16 \cdot 0$ & $24 \cdot 6$ & $12 \cdot 1$ & $31 \cdot 6$ & $11 \cdot 4$ \\
\hline$\beta$-Glucosidase & $5 \cdot 28$ & $2 \cdot 79$ & $6 \cdot 23$ & 1.53 & $5 \cdot 64$ & 1.78 & $5 \cdot 14$ & $2 \cdot 01$ & 6.06 & 0.98 \\
\hline$\alpha$-Galactosidase & 9.96 & 7.55 & 12.5 & $5 \cdot 0$ & $12 \cdot 9$ & $7 \cdot 22$ & $19 \cdot 8$ & 8.9 & 20.5 & $10 \cdot 0$ \\
\hline$\beta$-Galactosidase & $77 \cdot 3$ & $36 \cdot 2$ & $76 \cdot 2$ & $31 \cdot 7$ & $89 \cdot 3$ & $27 \cdot 9$ & $90 \cdot 1$ & 37.5 & 94.4 & $36 \cdot 0$ \\
\hline$\beta$-Glucuronidase & $6 \cdot 72^{\mathrm{a}}$ & 2.90 & $5 \cdot 47^{\mathrm{a}, \mathrm{b}}$ & 2.45 & $4 \cdot 64^{\mathrm{a}, \mathrm{b}}$ & $2 \cdot 24$ & $3.71^{\mathrm{b}}$ & $1 \cdot 17$ & $6 \cdot 23^{a, b}$ & 1.60 \\
\hline \multicolumn{11}{|c|}{ SCFA ( $\mu \mathrm{mol} / \mathrm{g}$ digesta) } \\
\hline Acetic acid & $57 \cdot 2$ & $17 \cdot 0$ & 44.5 & $9 \cdot 6$ & 47.4 & 8.6 & $46 \cdot 7$ & $14 \cdot 2$ & 53.5 & 11.5 \\
\hline Propionic acid & $39.8^{a}$ & $11 \cdot 0$ & $36 \cdot 3^{a, b}$ & $9 \cdot 3$ & $32 \cdot 5^{a, b}$ & $6 \cdot 0$ & $30 \cdot 3^{b}$ & 8.0 & $32 \cdot 4^{\mathrm{a}, \mathrm{b}}$ & $8 \cdot 4$ \\
\hline Iso-butyric acid & 0.17 & 0.12 & 0.14 & 0.12 & $0 \cdot 14$ & 0.06 & 0.09 & 0.06 & 0.13 & 0.05 \\
\hline Butyric acid & 8.54 & $6 \cdot 79$ & 5.02 & 3.35 & 4.97 & $3 \cdot 14$ & $5 \cdot 18$ & $3 \cdot 82$ & 5.55 & 3.42 \\
\hline Iso-valeric acid & 0.53 & 0.34 & 0.44 & 0.34 & 0.47 & 0.14 & 0.32 & 0.11 & 0.36 & 0.15 \\
\hline Valeric acid & 0.70 & 0.53 & 0.60 & 0.34 & 0.69 & 0.23 & 0.23 & 0.21 & 0.27 & 0.27 \\
\hline Total SCFA & 107 & 27 & $87 \cdot 0$ & $15 \cdot 4$ & $86 \cdot 2$ & 13.9 & $82 \cdot 8$ & $15 \cdot 3$ & $92 \cdot 2$ & $18 \cdot 2$ \\
\hline \multicolumn{11}{|c|}{ Profile (\% SCFA total) } \\
\hline $\mathrm{C}_{2}$ & 53 & 4 & 51 & 4 & 55 & 4 & 56 & 10 & 58 & 4 \\
\hline $\mathrm{C}_{3}$ & 38 & 8 & 41 & 5 & 38 & 4 & 37 & 9 & 35 & 5 \\
\hline $\mathrm{C}_{4}$ & 7 & 5 & 6 & 4 & 6 & 3 & 6 & 4 & 6 & 3 \\
\hline \multicolumn{11}{|c|}{ SCFA $(\mu \mathrm{mol} / 100 \mathrm{~g} \mathrm{BW})$} \\
\hline Acetic acid & $99 \cdot 0^{a, b}$ & 29.4 & $85 \cdot 2^{b}$ & $25 \cdot 8$ & $105^{a, b}$ & 38 & $118^{\mathrm{a}}$ & 36 & $106^{a, b}$ & 47 \\
\hline Propionic acid & $71 \cdot 7$ & $32 \cdot 7$ & $69 \cdot 9$ & $26 \cdot 7$ & 73.2 & $29 \cdot 4$ & 82.5 & $28 \cdot 2$ & $65 \cdot 3$ & $33 \cdot 6$ \\
\hline Iso-butyric acid & 0.27 & 0.18 & 0.26 & 0.21 & 0.30 & 0.16 & 0.23 & 0.12 & 0.26 & 0.16 \\
\hline Butyric acid & $13 \cdot 2$ & 9.7 & 8.73 & 4.60 & $10 \cdot 4$ & $5 \cdot 8$ & $13 \cdot 8$ & $14 \cdot 0$ & 11.43 & 8.27 \\
\hline Iso-valeric acid & 0.88 & 0.47 & $0 \cdot 81$ & 0.55 & 1.07 & 0.55 & 0.84 & 0.27 & 0.72 & 0.37 \\
\hline Valeric acid & $1 \cdot 24$ & 0.98 & 1.21 & 0.89 & $2 \cdot 07$ & 1.44 & 0.60 & 0.45 & 0.76 & $1 \cdot 23$ \\
\hline Total SCFA & $186^{\mathrm{a}, \mathrm{b}}$ & 56 & $166^{\mathrm{b}}$ & 47 & $192^{\mathrm{a}, \mathrm{b}}$ & 70 & $216^{a}$ & 67 & $184^{\mathrm{a}, \mathrm{b}}$ & 86 \\
\hline
\end{tabular}

C, control; PL, diet supplemented with $10 \%$ of root extract; PM, diet supplemented with $6.5 \%$ of peel extract; PH, diet supplemented with $8 \%$ of peel extract and $0.8 \%$ of seed extract; PMc, diet supplemented with $2.5 \%$ of leaf extract with $0.106 \%$ of total phenolics; BW, body weight.

${ }^{a, b}$ Mean values within a row with unlike superscript letters were significantly different $(P \leq 0.05)$. 
Table 6. Indices of antioxidant status and lipid metabolism in rats fed the diets supplemented with the chicory extracts (Mean values and standard deviations)

\begin{tabular}{|c|c|c|c|c|c|c|c|c|c|c|}
\hline & \multicolumn{2}{|c|}{ C } & \multicolumn{2}{|c|}{ PL } & \multicolumn{2}{|c|}{ PM } & \multicolumn{2}{|c|}{$\mathrm{PH}$} & \multicolumn{2}{|c|}{ PMc } \\
\hline & Mean & SD & Mean & SD & Mean & SD & Mean & SD & Mean & SD \\
\hline GPx $(\mathrm{mmol} / \mathrm{min}$ per I) & $23 \cdot 0$ & 3.3 & $24 \cdot 8$ & $5 \cdot 8$ & $22 \cdot 5$ & $2 \cdot 2$ & 23.9 & 5.9 & 24.5 & 3.4 \\
\hline $\mathrm{SOD}(\mathrm{mmol} / \mathrm{min}$ per $\mathrm{l})$ & 310 & 25 & 344 & 69 & 297 & 16 & 300 & 31 & 307 & 30 \\
\hline $\mathrm{ACW}^{*}$ & $0.062^{b}$ & 0.018 & $0.066^{a, b}$ & 0.029 & $0.075^{\mathrm{a}}$ & 0.017 & $0.066^{a, b}$ & 0.010 & $0.066^{a, b}$ & 0.022 \\
\hline ACL $†$ & $0.091^{a}$ & 0.013 & $0.091^{a}$ & 0.016 & $0.080^{\mathrm{b}}$ & 0.003 & $0.088^{a, b}$ & 0.009 & $0.090^{a, b}$ & 0.006 \\
\hline \multicolumn{11}{|l|}{$\begin{array}{l}\text { TBARS } \\
(\mu \mathrm{mol} / 100 \mathrm{~g} \text { tissue })\end{array}$} \\
\hline Kidney & $12 \cdot 8$ & $2 \cdot 9$ & $12 \cdot 0$ & $1 \cdot 8$ & $12 \cdot 1$ & $1 \cdot 1$ & $11 \cdot 3$ & 1.6 & $12 \cdot 3$ & 0.7 \\
\hline Liver & 7.05 & 0.61 & $7 \cdot 15$ & 0.38 & $6 \cdot 95$ & 0.43 & $6 \cdot 90$ & 0.44 & 7.06 & 0.57 \\
\hline Heart & $6 \cdot 76$ & 0.23 & $7 \cdot 01$ & 0.65 & $6 \cdot 80$ & 0.62 & 6.93 & 0.63 & $6 \cdot 86$ & 0.54 \\
\hline Lungs & $8.55^{\mathrm{a}}$ & 0.62 & $8 \cdot 04^{a, b, c}$ & 0.97 & $8 \cdot 40^{a, b}$ & 0.27 & $7 \cdot 29^{c}$ & 0.91 & $7 \cdot 51^{b, c}$ & 0.84 \\
\hline \multicolumn{11}{|l|}{ Serum } \\
\hline Glucose (mg/l) & 2480 & 300 & 2410 & 700 & 2490 & 340 & 2430 & 390 & 2440 & 540 \\
\hline TAG (mg/l) & 1990 & 330 & 1890 & 580 & 2110 & 640 & 2020 & 450 & 1680 & 780 \\
\hline Cholesterol (mg/l) & $1250^{a, b}$ & 130 & $1350^{a, b}$ & 240 & $1410^{a, b}$ & 270 & $1470^{\mathrm{a}}$ & 120 & $1250^{\mathrm{b}}$ & 170 \\
\hline $\mathrm{HDL}(\mathrm{mg} / \mathrm{l})$ & 547 & 97 & 518 & 88 & 557 & 33 & 526 & 25 & 548 & 44 \\
\hline $\begin{array}{l}\text { HDL/total } \\
\text { cholesterol (\%) }\end{array}$ & $43 \cdot 6^{a, b}$ & $5 \cdot 4$ & $38 \cdot 8^{\mathrm{a}, \mathrm{b}}$ & $5 \cdot 2$ & $41 \cdot 0^{\mathrm{a}, \mathrm{b}}$ & $9 \cdot 0$ & $35 \cdot 9^{b}$ & $3 \cdot 6$ & $44 \cdot 9^{a}$ & $8 \cdot 2$ \\
\hline
\end{tabular}

C, control; PL, diet supplemented with $10 \%$ of root extract; PM, diet supplemented with $6.5 \%$ of peel extract; $\mathrm{PH}$, diet supplemented with $8 \%$ of peel extract and $0.8 \%$ of seed extract; PMc, diet supplemented with $2.5 \%$ of leaf extract with $0.106 \%$ of total phenolics; GPx, glutathione peroxidase; SOD, superoxide dismutase; ACW, antioxidant capacity of water-soluble substances in the plasma; ACL, antioxidant capacity of lipid-soluble substances in the plasma; TBARS, thiobarbituric acid-reactive substances.

${ }^{a, b, c}$ Mean values within a row with unlike superscript letters were significantly different $(P \leq 0.05)$.

${ }^{*} \mu \mathrm{mol}$ ascorbic acid equivalents $/ \mathrm{ml}$ of serum.

$\dagger \mu \mathrm{mol}$ Trolox equivalents $/ \mathrm{ml}$ of serum.

the ecosystem of the caecum and the colon ${ }^{(2)}$. Investigations have demonstrated that after the ingestion of a DCQA-rich diet, those compounds both rapidly appear in the blood and are removed from it. This is due to the fact that methyl and glucuronic metabolites of those acids as well as DCQA themselves do appear in urine at the same time ${ }^{(21)}$. In the discussed experiment, the chicory extracts applied in the diet had no negative effect on jejunal disaccharidase activity, which indicates undisturbed absorption of carbohydrates from the gastrointestinal tract. Activities of intestinal disaccharidases - maltase, lactase and sucrase - are linked with intestinal epithelium development and with the likely occurrence of damage to the epithelial tissue ${ }^{(22)}$.

It is estimated that about one-third of the ingested chlorogenic acid is absorbed in the small intestine of humans ${ }^{(23)}$. The remainder reaches the large intestine, where it is metabolised by bacteria. A few strains of bacteria belonging to Escherichia coli, Lactobacillus (e.g. L. gasseri) and Bifidobacterium (e.g. B. lactis) have been identified as colonising the gastrointestinal tract of humans and to be capable of synthesising esterase which hydrolyses chlorogenic acids ${ }^{(19)}$. In addition, chlorogenic and caffeic acids have been shown to exert strong inhibiting effects against the growth of selected strains of Streptococcus and enterobacteria, with their impacts in some cases being multiply stronger than those of $(-)$-epicatechin and ( - )-epigallocatechin extracted from green tea ${ }^{(24)}$. Having been released from chlorogenic acid by enzymes of the small intestine or bacterial esterase, caffeic acid may undergo further modifications, e.g. it may link with glucuronic acid, mainly in the liver, but also in the small and large intestine. Unfortunately, the linking of phenolic acids with glucuronic acid diminishes significantly their antioxidative properties ${ }^{(2)}$. On the other hand, bacterial $\beta$-glucuronidase may re-hydrolyse binding with glucuronic acid, thus releasing bioactive compounds.

The reported experiment demonstrated the desirable, selective influence of the fructan-polyphenolic preparations on microbial enzymatic activity in the caecum and faeces of rats. The phenolic fraction was found not to inhibit the activity of the glycolytic enzymes released into the environment analysed in the caecal digesta, i.e. $\alpha$ - and $\beta$-galactosidase and $\alpha$ - and $\beta$-glucosidase. A contrary effect of chicory polyphenols was observed in the case of bacterial $\beta$-glucuronidase activity in the faeces and caecal digesta. It tended to diminish in the experimental groups, with the strongest inhibiting effect observed for the highest levels of diet supplementation with a mixture of MCQA and DCQA. It may be speculated that this was an additional effect of a dietary treatment with, besides fructans, a relatively high amount of the polyphenolic fraction. Some studies have demonstrated that phenolic acids are likely to exert a positive effect, synergistic with impacts of other biologically active compounds of the diet ${ }^{(25)}$. Also, in studies on biological properties of other classes of polyphenols, metabolism of the large intestine has been found to be positively affected by a prebiotic-phenolic mixture compared with supplements applied separately ${ }^{(26,27)}$. The activity of microbiological $\beta$-glucuronidase is claimed to be a biomarker of an increased risk of neoplasm incidence ${ }^{(16)}$. 
The greatest increase in the digesta bulk in the caecum was observed in rats fed the $\mathrm{PH}$ diet containing MCQA and DCQA at the level of $0.21 \%$, which confirms the earlier findings that polyphenols may increase digesta hydration and delay digesta passage, thus increasing their accumulation and, indirectly, increasing the mass of the intestinal wall $^{(26,27)}$. The extracts prepared from different parts of chicory did not trigger any significant changes in the total caecal SCFA concentration. In a study by Zduńczyk et $a{ }^{(26)}$, the presence of grapefruit polyphenols in inulin-containing diets was also observed not to change the caecal SCFA concentration in rats. In the reported experiment, only the diet with the highest level of MCQA and DCQA significantly diminished the concentration of propionic acid and increased the caecal acetic acid pool. The above changes in the caecal concentrations of SCFA were consistent with blood markers of the lipid profile of the rats from the $\mathrm{PH}$ group. Propionate is claimed to be involved in the cholesterol-lowering effect of fibres by impairing acetate utilisation, especially when cholesterol synthesis is activated to compensate for enhanced faecal losses of steroids ${ }^{(28)}$

A number of authors have reported that plants containing both prebiotic carbohydrates and a rich phenolic fraction demonstrate, apart from strong antioxidative properties, a positive effect on the lipid profile, including a decreased cholesterol concentration ${ }^{(26,27)}$. A study with volunteers has confirmed the mild hypocholesterolaemic effect of an artichoke extract rich in 1,3-DCQA (cinarine), at the dosage of $500-1500 \mathrm{mg}$ of cinarine $/ \mathrm{d}^{(29)}$. In the discussed experiment, the expected favourable effect of the polyphenolic fraction on the glucose level and the lipid profile of the blood serum was not observed due to the analogous action of the fructan fraction, whose modulatory impact on lipid metabolism has already been well documented $^{(6,16)}$. The lowest total cholesterol concentration and the highest value of the HDL-cholesterol profile in the PMc group may point to a more beneficial effect of the leaf extract compared with the extract prepared from chicory roots. It may, thus, be speculated that such an effect was due to compounds absent in the root extract, namely chicoric acid and/or polyphenolic glycosides.

Phenolic compounds are claimed to be capable of interrupting processes of chain auto-oxidation of free radicals ${ }^{(20)}$. Using the diphenylpicryl hydrazine method, it has been demonstrated that the main components of an ethanolic extract from Cratoxylum formosum, i.e. chlorogenic acid, DCQA and ferulic acid, display similar antioxidative properties, and that the whole extract was a stronger scavenger of free radicals than model antioxidants, such as $\alpha$-tocopherol and butylated hydroxytoluene ${ }^{(30)}$. However, in another experiment, with the use of a LDL-cholesterol oxidation test conducted for preparations from different parts of artichoke obtained with two extraction methods, the antioxidative activity was not highly correlated with the content of total polyphenols in the extract ${ }^{(31)}$. This, in turn, points to a varied antioxidative potential of different polyphenolic fractions or to a significant effect of the extraction method on the antioxidative properties of resultant preparations. The results obtained in the present study with respect to the TBARS level in the bodies of rats show that the content of chicory polyphenols in a diet affects the antioxidative status of the lungs - an organ being highly exposed to lipid peroxidation. Diet supplementation with a mixture of MCQA and DCQA originating from the extracts prepared from root peels and seeds of chicory at a level of $0.21 \%$ diet as well as diet supplementation with the extract of leaves $(0 \cdot 11 \%$ diet $)$ considerably reduced the TBARS concentration in the lungs. Worthy of note is the fact that the results discussed herein refer to an experiment conducted with healthy rats, which additionally emphasises the considerable antioxidative potential in vivo of the polyphenolic fraction of chicory. In the discussed study, the experimental treatments had no effect on glutathione peroxidase and superoxide dismutase activities in the blood. In contrast, in the group with the medium level of diet supplementation with MCQA and DCQA, unexpected differences were observed in the values of $\mathrm{ACW}$ and $\mathrm{ACL}$ parameters, i.e. respectively the highest and the lowest value out of all groups examined. The tendencies observed were, however, not confirmed at the lower or higher level of the polyphenolic fraction in the diet. A number of authors have pointed to noticeable discrepancies in values of selected (superoxide dismutase, glutathione peroxidase, ACW and ACL) parameters characterising the antioxidative status of a body exposed to the oxidative stress $^{(32,33)}$. For this reason, a reliable evaluation of the effect of phytocompounds on the health status of the body should be based on a complex analysis of multiple metabolic markers of blood and peripheral tissues.

\section{Conclusions}

In the summary of the discussed experiment, it may be concluded that the applied addition of the polyphenolic fraction to diets containing prebiotic fructans did not diminish the positive effect of inulin and oligofructose on the ecosystem of the gastrointestinal tract and other functional parameters of the laboratory animals. An additional effect of diet supplementation with the extracts from chicory roots and seeds, especially at the highest level of supplementation with MCQA and DCQA reaching $0.21 \%$ diet, induced beneficial changes in parameters of the oxidative status of the body and in bacterial $\beta$-glucuronidase activity in the faeces and caecal digesta. Some of the physiological parameters analysed indicate that increasing doses of the polyphenols in the diet may - to some extent - disturb metabolism in the distal section of the gastrointestinal tract, i.e. evoke excessive accumulation of hydrated intestinal digesta. Diet supplementation with an extract from chicory leaves containing considerable 
quantities of chicoric acid and polyphenolic glycosides, apart from chlorogenic acids, also triggered positive changes in the lipid profile of blood serum as well as deceleration of pro-oxidative processes in lung tissue. In contrast, no positive effect of the leaf extract was observed with respect to the activity of bacterial $\beta$-glucuronidase released into the environment and acidification of caecal digesta.

\section{Acknowledgements}

The authors declare no conflicts of interest and take responsibility for the integrity of the data and the accuracy of the analyses. J. J. and Z. Z. were involved in the conception of the study; B. K. and J. M. prepared the extracts and their chemical characteristics; J. J., E. Z.-S. and A. J. were involved in the collection and assembly of the data and the analysis of the physiological response; J. J. and E. Ż.-S. prepared the manuscript and performed the statistical analyses. Critical revision of the text was completed by all the authors. This research received no specific grant from any funding agency in the public, commercial or not-for-profit sectors.

\section{References}

1. Fratianni F, Tucci M, De Palma M, et al. (2007) Polyphenolic composition in different parts of some cultivars of globe artichoke (Cynara cardunculus L. var. scolymus (L.) Fiori). Food Chem 104, 1282-1286.

2. Olthof MR, Hollman PCH \& Katan MB (2001) Chlorogenic acid and caffeic acid are absorbed in humans. J Nutr $\mathbf{1 3 1}$, 66-71.

3. Kono Y, Shibata H, Kodama Y, et al. (1995) The suppression of the N-nitrosating reaction by chlorogenic acid. Biochem J 312, 947-953.

4. Balasundram N, Sundram K \& Samman S (2006) Phenolic compounds in plants and agri-industrial by-products: antioxidant activity, occurrence, and potential uses. Food Chem 99, 191-203.

5. Nardini M, D'Aquino M, Tomassi G, et al. (1995) Inhibition of human low-density lipoprotein oxidation by caffeic acid and other hydroxycinnamic acid derivatives. Free Radic Biol Med 19, $541-552$.

6. Rodriguez D \& Hadley M (2002) Chlorogenic acid modifies plasma and liver concentrations of: cholesterol, triacylglycerol, and minerals in $(f a / f a)$ Zucker rats. $J$ Nutr Biochem 13, 717-726.

7. Yashimoto M, Yahara S, Okuno S, et al. (2002) Antimutagenicity of mono-, di-, and tricaffeoylquinic acid derivatives isolated from sweetpotato (Ipomoea batatas L.) leaf. Biosci Biotechnol Biochem 66, 2336-2341.

8. Slanina J, Taborska E, Slaninova I, et al. (2001) New and facile method of preparation of the anti-HIV-1 agent, 1,3dicaffeoylquinic acid. Tetrahedron Lett 42, 3383-3385.

9. Milala J, Grzelak K, Król B, et al. (2009) Composition and properties of chicory extracts rich in fructans and polyphenols. Pol J Food Nutr Sci 59, 35-43.

10. AOAC (Association of Official Analytic Chemists) (2005) Official Methods of Analysis of the Association of the Official Analytical Chemists, 18th ed. Arlington, VA: AOAC.
11. Król B \& Grzelak K (2006) Qualitative and quantitative composition of fructooligosaccharides in bread. Eur Food Res Technol 233, 755-758.

12. Scarpati ML \& Oriente G (1958) Chicoric acid (dicaffeyltartic acid), its isolation from chicory (Cichorium intybus) and synthesis. Tetrahedron 4, 43-48.

13. Chkhikvishvili JD \& Kharebova GI (2000) Chicoric and chlorogenic acids in plant species from Georgia. Appl Biochem Microbiol 37, 188-191.

14. Mulinacci N, Innocenti M, Gallori S, et al. (2001) Optimization of the chromatographic determination of polyphenols in the aerial parts of Cichorium intybus L. Chromatographia 54, 455-461.

15. Messer M \& Dahlqvist A (1966) A one-step ultramicro method for the assay of intestinal disaccharidases. Anal Biochem 14, 376-392.

16. Juśkiewicz J, Wróblewska M, Jarosławska J, et al. (2009) Effects of inulin supplemented to cellulose-free or celluloserich diets on caecal environment and biochemical blood parameters in rats. J Anim Feed Sci 18, 709-722.

17. Uchiyama M \& Mihara M (1978) Determination of malonaldehyde precursor in tissues by thiobarbituric acid test. Anal Biochem 86, 271-278.

18. Schmidt B, Nebojsa I, Poulev A, et al. (2007) Toxicological evaluation of a chicory root extract. Food Chem Toxicol 45, 1131-1139.

19. Couteau D, McCartney AL, Gibson GR, et al. (2001) Isolation and characterization of human colonic bacteria able to hydrolyse chlorogenic acid. J Appl Microbiol 90, 873-881.

20. Llorach R, Tomas-Barberan FA \& Ferreres F (2004) Lettuce and chicory byproducts as a source of antioxidant phenolic extracts. J Agric Food Chem 52, 5109-5116.

21. Yang B, Meng ZY, Yan LP, et al. (2006) Pharmacokinetics and metabolism of 1,5-dicaffeoylquinic acid in rats following a single intravenous administration. J Pharm Biomed Anal 40, 417-422.

22. Chau CF, Sheu F, Huang Y, et al. (2005) Improvement in intestinal function and health by the peel fibre derived from Citrus sinensis L. cv. Liucheng. J Sci Food Agr 85 1211-1216.

23. Choudhury R, Srai SK, Debnam E, et al. (1999) Urinary excretion of hydroxycinnamates and flavonoids after oral and intravenous administration. Free Radical Biol Med 27, 278-286.

24. Tsai TH, Tsai TH, Chien YC, et al. (2008) In vitro antimicrobial activities against cariogenic streptococci and their antioxidant capacities: a comparative study of green tea versus different herbs. Food Chem 110, 859-864.

25. Svilaas A, Sakhi AK, Andersen LF, et al. (2004) Intakes of antioxidants in coffee, wine, and vegetables are correlated with plasma carotenoids in humans. J Nutr 134, 562-567.

26. Zduńczyk Z, Juśkiewicz J \& Estrella I (2006) Cecal parameters of rats fed diets containing grapefruit polyphenols and inulin as single supplements or in a combination. Nutrition 22, 898-904.

27. Aprikian O, Duclos V, Guyot S, et al. (2003) Apple pectin and a polyphenol-rich apple concentrate are more effective together than separately on caecal fermentation and plasma lipids in rats. J Nutr 133, 1860-1865.

28. Demigné C, Morand C, Levrat MA, et al. (1995) Effect of propionate on fatty acid and cholesterol synthesis and on acetate metabolism in isolated rat hepatocytes. $\mathrm{Br} J \mathrm{Nutr}$ 74, 209-219.

29. Clifford MN (2000) Chlorogenic acids and other cinnamates - nature, occurence, dietary burden, absorption and metabolism. J Sci Food Agric 80, 1033-1043. 
30. Maisuthisakul P, Pongsawatmanit R \& Gordon MH (2007) Characterization of the phytochemicals and antioxidant properties of extracts from Teaw (Cratoxylum formosum Dyer). Food Chem 100, 1620-1629.

31. Coinu R, Carta S, Urgeghe PP, et al. (2007) Dose-effect study on the antioxidant properties of leaves and outer bracts of extracts obtained from Violetto di Toscana artichoke. Food Chem 101, 524-531.
32. Ugochukwu NH, Bagayoko ND \& Antwi ME (2004) The effects of dietary caloric restriction on antioxidant status and lipid peroxidation in mild and severe streptozotocininduced diabetic rats. Clin Chim Acta 348, 121-129.

33. Juśkiewicz J, Zduńczyk Z, Jurgoński A, et al. (2008) Extract of green tea leaves partially attenuates streptozotocin induced changes in antioxidant status and gastrointestinal functioning in rats. Nutr Res 28, 343-349. 